\title{
Menstimulasi Peserta Didik yang Mengalami Kesulitan Belajar Membaca Permulaan di Sekolah Dasar
}

\author{
Rossi Iskandar ${ }^{1 *}$, Zulela MS ${ }^{2}$, Fahrurrozi ${ }^{3}$ \\ ${ }^{1}$ Jurusan Pendidikan Guru SD, Fakultas Keguruan dan Ilmu Pendidikan, Universitas Trilogi, Indonesia \\ 2,3 Jurusan Pendidikan Guru SD, Fakultas Ilmu Pendidikan, Universitas Negeri Jakarta, Indonesia
}

\section{ART I CLE IN F O}

\section{Article history:}

Received March 09, 2021

Revised April 15, 2021

Accepted April 30, 2021

Available online July 25, 2021

\section{Kata Kunci:}

Kesulitan Belajar, Membaca Permulaan, Sekolah Dasar

Keywords:

Difficulty Learning,

Beginning Reading,

Elementary School

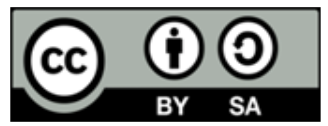

This is an open access article under the CC BY-SA license.

Copyright $\left({ }_{0} 2021\right.$ by Author. Published by Universitas Pendidikan Ganesha.

\begin{abstract}
A B S T R A K
Siswa masih sulit membedakan bentuk huruf dan sulit membaca huruf konsonan yang ada di belakang. Faktor penyebab kesulitan membaca adalah dari kesulitan persepsi visual, kesulitan persepsi auditori, masalah neurologis dan Dyslexia. Tujuan penelitian ini yaitu menganalisis permasalahan yang terjadi pada siswa sehingga mengalami kesulitan membaca permulaan. Jenis penelitian ini yaitu kualitatif. Teknik pengumpulan data dengan cara observasi, wawancara dan angket dengan alat assessmen yang mengacu pada buku kesulitan belajar: perspektif, asessmen dan penanggulangannya. Subjek dalam penelitian ini adalah kelas rendah di sekolah dasar dengan jumlah 25 peserta didik yang teridentifikasi mengalami kesulitan membaca permulaan. Metode kualitatif dengan pendekatan analisis deskriftif digunakan untuk menganalisis data. Hasil menunjukan assessmen perseptual yang digunakan terhadap peserta didik adalah berupa visual discrimination, figure-ground, visual closure, dan spatial relationship. Persepsi auditori berupa auditory discrimination, auditory memory serta masalah neurologis. Melalui analisis proses kegiatan pembelajaran menstimulasi peserta didik yang mengalami kesulitan membaca permulaan diperlukan kegiatan penelitian lanjutan dalam mengembangkan sebuah media pembelajaran yang lebih inovatif, bergambar dan terintegrasi audio visual. Hasil penelitian ini hanya menganalisis kesulitan belajar membaca permulaan dilihat dari kegiatan dan aktifitas proses pembelajaran dan serta kebutuhan guru.
\end{abstract}

\section{A B S T R A C T}

Students still find it difficult to distinguish the shape of the letters, and it is difficult to read the consonants on the back. The factors that cause reading difficulties are visual perception difficulties, auditory perception difficulties, neurological problems and dyslexia. This study aims to analyze the problems that occur in students so that they have difficulty reading the beginning. This type of research is qualitative. The collecting data is using observation, interviews and questionnaires with an assessment tool that refers to the book of learning difficulties: perspectives, assessments and overcoming them. The subjects in this study were lowgrade elementary schools, with 25 students identified as having difficulty reading at the beginning. Qualitative methods with a descriptive analysis approach were used to analyze the data. The results show that the perceptual assessment used for students is in the form of visual discrimination, figure-ground, visual closure, and spatial relationships-auditory perception in the form of auditory discrimination, auditory memory and neurological problems. By analyzing the process of learning activities to stimulate students who have difficulty reading the beginning, other research activities are needed in developing a more innovative learning media, illustrated and integrated with audio-visual. The results of this study only analyzed the difficulty of learning to read the beginning seen from the activities and activities of the learning process and the needs of teachers.

\section{PENDAHULUAN}

Kegiatan membaca adalah kemampuan dalam mengingat simbol-simbol grafis yang berbentuk huruf, mengingat bunyi menulis simbol-simbol grafis dalam rangkaian kata dan kalimat yang mengandung makna (Aydın \& Bağcl Ayrancl, 2018; Nugrahanto \& Zuchdi, 2019; Tse et al., 2019). Landasan kemampuan membaca adalah kemampuan kognitif (Bursali \& Yilmaz, 2019; Rajab \& Al-Sadi, 2015). Dalam penelitian terdahulu sekitar 70\% dari peserta didik sekolah dasar membutuhkan beberapa bentuk instruksi perbaikan membaca (Calhoon et al., 2010). Kemampuan memusatkan perhatian merupakan kegiatan dalam membaca, tanpa kemampuan ini sulit 
bagi seseorang untuk merangkai simbol-simbol grafis yang berbentuk huruf menjadi kata atau kalimat yang mengandung makna (Akın et al., 2015; Memiş \& Kandemir, 2019; Vuong et al., 2019). Bagian dari kemampuan membaca adalah proses presepsi yang berperan dalam pembentukan kemampuan membaca yaitu diskriminasi auditori, diskriminasi visual, kemampuan mengintegrasikan diskriminasi visual dan diskriminasi auditori (Kurniawati \& Koeswanti, 2020; Saonah, 2018). Hal tersebut yang menyebabkan kemampuan membaca dipengaruhi oleh proses persepsi dan kemampuan kognitif. Namun dalam kenyataanya, peserta didik yang ada di kelas rendah masih sulit membedakan bentuk huruf dan sulit membaca huruf konsonan yang ada di belakang (Amini \& Suyadi, 2020; Christianti, 2013). Masih banyak merasa kesulitan atas konsep simbol dan alphabet (Darnis, 2018; Rekysika \& Haryanto, 2019). Faktor penyebab kesulitan membaca adalah dari kesulitan persepsi visual, kesulitan persepsi auditori, masalah neurologis dan Dyslexia (Talebi \& Marzban, 2015; Zarić et al., 2021). Klasifikasi dari kesulitan belajar adalah 1) kesulitan mendengar; (2) kesulitan dalam melakukan ekspresi secara lisan; (3) kesulitan membaca (4) kesulitan menulis dan mengarang; (5) kesulitan matematika yaitu kesulitan dalam kalkulasi dan hitungan soal (Chukwu et al., 2019; Cluley, 2018; Cluley et al., 2020).

Tahapan dalam membaca permulaan dimulai di kelas awal Sekolah Dasar (P. H. Lin et al., 2019; Zarić et al., 2021). Anak mulai mempelajari kosa kata dan belajar membaca dalam waktu bersamaan (Gading et al., 2019). Kemampuan membaca yang diperoleh pada membaca permulaan akan sangat berpengaruh terhadap kemampuan membaca berikutnya (Bursali \& Yilmaz, 2019; Suwana et al., 2013). Kemampuan ini memerlukan perhatian dari guru yang mengajar, dan akan sangat berpengaruh terhadap tahap membaca lanjut (Memiş \& Kandemir, 2019; Vuong et al., 2019). Penelitian terbaru tentang membaca berfokus pada bagaimana membangun kemampuan cara membaca dan pertumbuhan membaca yang relevan untuk membangun tujuan dan media pembelajaran yang cocok digunakan dalam mencegah kesulitan membaca (Akın et al., 2015; P. H. Lin et al., 2019). Penyebab dari kesulitan belajar membaca adalah kurang memadai fasilitas dalam identifikasi kata (Capellini et al., 2015). Maka diperlukan guru yang sungguh-sungguh dan melaksanakan kegiatan pembelajaran. Kesulitan belajar merupakan istilah umum yang terjadi pada peserta didik sekolah dasar berkaitan dengan fakta yang terjadi seperti tinggal kelas ataupun rendahnya nilai pelajaran yang di ikutinya (Widyaningrum \& Hasanudin, 2019; Yulianingsih et al., 2020). Kesulitan belajar adalah istilah umum yang mengacu pada sekelompok heterogen, kesulitan dalam perolehan dan penggunaan fisik dalam mendengar, berbicara, menulis, dan matematika (McGill-Franzen \& Allington, 2010). Belajar adalah suatu perubahan tingkah laku yang terus menerus timbul sebagai akibat dari persyaratan kondisi, dan sifatnya adalah membentuk hubungan stimulus dan respons (L. Lin \& Li, 2018; Valverde-Berrocoso et al., 2020). Salah satu faktor yang menyebabkan siswa mengalami kesulitan belajar yaitu rendahnya minat siswa dalam membaca (Akın et al., 2015; Nani \& Evinna, 2019).

Temuan penelitian sebelumnya menyatakan bahwa rendahnya minat siswa dalam belajar akan mempengaruhi perkembangan kognitif anak (Mayarnimar \& Taufina, 2017; Reilly, 2021). Temuan penelitian lainnya juga menyatakan bahwa siswa yang memiliki minat untuk membaca akan meningkatkan kemampuan berpikir kritis pada siswa (Haromi, 2014; Heidari, 2020; Talebi \& Marzban, 2015). Hal ini menandakan bahwa kegiatan membaca sangat berpengaruh pada kemampuan kognitif siswa. Berdasarkan permasalahan tersebut maka diperlukan sebuah solusi untuk mengatasi permasalahan tersebut. Tujuan penelitian ini yaitu menganalisis permasalahan yang terjadi pada siswa sehingga mengalami kesulitan membaca permulaan. Diharapkan penelitian ini dapat membantu guru dalam menemukan solusi untuk mengatasi kesulitan membaca permulaan pada siswa.

\section{METODE}

Jenis penelitian ini yaitu kualitatif. Penelitian ini merupakan serangkaian pengumpulan data kepustakaan, atau penelitian di mana objek penelitian dieksplorasi melalui berbagai informasi perpustakaan (buku, ensiklopedia, jurnal ilmiah, surat kabar, majalah, dan dokumen). Subjek penelitian ini adalah peserta didik sekolah dasar kelas rendah dengan jumlah 159 siswa. Hasil penilaian dari kemampuan persepsi teridentifikasi 25 peserta didik mengalami kesulitan belajar membaca. Data yang digunakan dalam penelitian ini adalah data sekunder. Data sekunder adalah data yang diperoleh bukan dari pengamatan langsung. Namun, data-data ini diperoleh dari hasil penelitian yang telah dilakukan peneliti sebelumnya. Pendekatan yang digunakan dalam penelitian ini adalah pendekatan filosofis dan pedagogis menggunakan model Milles dan Huberman, melalui model analisis data tiga langkah, yaitu: (1) pengurangan data; (2) penyajian data; (3) mengambil kesimpulan. Metode pengumpulan data yang digunakan adalah studi literatur, observasi dan wawancara terhadap 20 guru di sekolah dasar. Peneliti memperoleh data terkait subjek penelitian ini menggunakan berbagai informasi perpustakaan (buku, ensiklopedia, jurnal ilmiah, surat kabar, majalah, dan dokumen). Teknik analisis data penelitian ini adalah teknik analisis data kualitatif. Dengan menganalisis aktifitas dan proses kegiatan belajar, wawancara dengan guru. 


\section{HASIL DAN PEMBAHASAN}

Hasil

Penelitian ini dilakukan di kelas rendah dengan mengamati perilaku dan karakteristik peserta didik di Sekolah Dasar yang mengalami kesulitan belajar membaca permulaan dan mengetahui serta mengidentifikasi karakteristik peserta didik ketika belajar di sekolah. Tahapan yang dilakukan adalah mengamati lingkungan kelas baik secara fisik dan sosial, mengamati hasil membaca peserta didik selama mengikuti kegiatan membaca bersama guru, mendiskusikan hasil pengamatan kepada guru dan kepala sekolah untuk meminta persetujuan perlunya dilakukan diagnosis, menyiapkan bahan diagnosis/ alat assessment peserta didik yang mengalami kesulitan belajar membaca permulaan. Selanjutnya, teknik pengumpulan informasi adalah dengan melakukan survey media pembelajaran sudah ada, sehingga dapat dijadikan rekomendasi dalam pengembangan media pembelajaran yang ada nilai inovasinya. Peneliti melakukan survey media di Sekolah inklusi, toko buku multimedia dan internet. Survey dilakukan untuk melihat kebutuhan media. Hasil analisis kebutuhan diperoleh nilai keseluruhan 928 dengan katagori sangat tinggi dari indeks kebutuhan media 800-1000. Berikut tabel hasil survey analisis kebutuhan. Berdasarkan hasil analisis data, 20 responden dengan 10 item pertanyaan guru membutuhkan media yang terintegrasi audio visual sebagai alat untuk membantu menstimulasi peserta didik dalam pembelajaran. selanjutnya peneliti melakukan wawancara terhadap guru kelas Sekolah Dasar untuk mengetahui beberapa hal, yaitu a) mengetahui alasan seorang anak mengalami kesulitan belajar membaca permulaan; b) mengetahui faktor-faktor yang menyebabkan anak mengalami kesulitan belajar membaca permulaan; c) mengetahui hal-hal yang dibutuhkan dalam melakukan treatment; d) megetahui media yang tepat dan sangat dibutuhkan oleh peserta didik yang mengalami kesulitan belajar membaca permulaan. Peneliti menggunakan wawancara yang terstruktur.

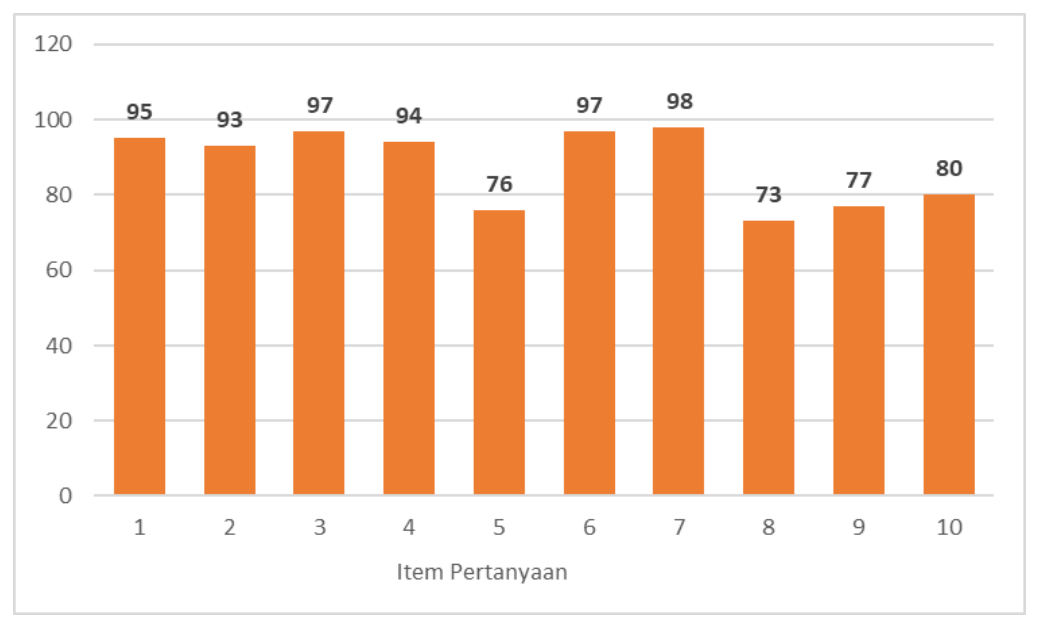

Gambar. 1 Hasil Analisis Kebutuhan

Hasil wawancara yang dilakukan kepada 10 guru, didapatkan bahwa peserta didik sering terbalik membedakan huruf contohnya antara huruf " $n$ " dan huruf " $m$ ". 4 orang guru mengatakan Namun ada juga peserta didik sulit dalam mengikuti perintah yang diberikan secara lisan, 4 orang guru mengatakan peserta didik sering mengalami kesulitan dalam mengungkapkan pikiran secara tertulis, dan 2 orang guru mengatakan peserta didik mengalami kesulitan dalam menentukan arah kiri dan kanan. Berdasarkan pertanyaan tersebut 10 orang guru mengatakan seharusnya disediakan fasilitas media dan metode yang akan membantu proses membaca, 5 orang guru mengatakan peserta didik diberi latihan membaca setiap hari kepada peserta didik, 2 orang guru mengatakan peserta didik diberi tugas yang lebih kepada orang tua di rumah untuk membantu membaca dan 2 orang guru mengatakan peserta didik diberikan latihan hanya sesuai buku baca. Mencermati temuan di atas tentunya perlu ada solusi dan cara yang dilakukan oleh guru dalam menstimulasi kesulitan belajar membaca permulaan yang terintegrasi.

\section{Pembahasan}

Berdasarkan hasil analisis data maka dapat disimpulkan bahwa peserta didik mengalami mengalami kesulitan dalam membedakan simbol ataupun kalimat sesuai dengan apa yang disampaikan. Selain itu minat siswa terhadap membaca juga rendah sehingga siswa memiliki kemampuan yang rendah (Chotitham \& Wongwanich, 2014; Peura et al., 2021). 25 peserta didik mengalami kesulitan belajar membaca permulaan setelah melihat hasil assessment dari kemampuan persepsi berupa visual discrimination, figure-ground, visual closure, dan spatial relationship. Persepsi auditori berupa auditory discrimination, auditory memory serta masalah neurologis. Temuan ini sesuai dengan penelitian sebelumnya yang menyatakan bahwa salah satu faktor 
penyebab kesulitan membaca adalah dari kesulitan persepsi visual, kesulitan persepsi auditori, masalah neurologis, Dyslexia (Baba \& Rostam Affendi, 2020; Nootens et al., 2019; Pilkington et al., 2019). Melalui penelitian diketahui guru sudah menggunakan metode yang bervariasi namun belum pernah membuat media yang digunakan dalam proses pembelajaran, guru hanya mengandalkan dari buku paket ataupun sumber referensi lain. Metode pembelajaran yang bervariasi juga akan meningkatkan semangat siswa dalam belajar (Balan et al., 2019; Nurtanto et al., 2019; Suryawati et al., 2020). Namun kurangnya media pembelajaran juga akan berpengaruh kepada proses pembelajaran (Febliza \& Okatariani, 2020; Hamid et al., 2017; Rabgay, 2018).

Hasil assesment dari kemampuan persepsi dan diskriminasi visual dapat diajarkan oleh guru dengan mengamati gambar-gambar pada majalah, buku dengan berbagai bunyi huruf didalamnya. Keterbatasan guru menjadi salah satu kesulitan untuk mengembangkan media (Friedman \& Friedman, 2013; Nurrohmah et al., 2018). Berdasarkan hasil wawancara di temukan bahwa 50\% dari responden menyatakan perlu melakukan pengembangan media pembelajaran dan $60 \%$ dari responden menjawab bentuk media audio visual yang diharapkan mampu menstimulasi peserta didik yang memiliki kesulitan belajar membaca permulaan. Selain itu dari wawancara yang dilakukan peserta didik sering terbalik membedakan huruf contohnya antara huruf " $\mathrm{n}$ " dan huruf " $m$ ", terkadang peserta didik sulit dalam mengikuti perintah yang diberikan secara lisan. Selanjutnya, cara guru yang dilakukan dalam menstimulasi adalah dengan menyediakan fasilitas media dan metode yang akan membantu proses membaca dan diberi latihan membaca setiap hari kepada peserta didik. Kegiatan tersebut juga akan mengatasi kesulitan belajar pada siswa (Azis, 2019; Oktadiana, 2019; Windrawati et al., 2020).

Mencermati hal tersebut berbagai faktor yang mempengaruhi kesulitan belajar membaca permulaan perlu dicarikan solusinya melalui pengembangan studi lanjut untuk menstimulasi kesulitan belajar membaca baik dengan media, model ataupun pendekatan lain yang memang bisa digunakan (Hermansyah et al., 2019; Widyowati et al., 2020; Yunita et al., 2017). Media pembelajaran yang disusun secara sistematis menyesuaikan antara karakteristik peserta didik dengan tingkat membaca permulaan (Amini \& Suyadi, 2020; Maula \& Fatmawati, 2020). Melalui hasil penelitian ini merekomendasikan bahwa di perlukan suatu pengembangan model baru, startegi ataupun media sebagai sarana alternatif untuk membantu menstimulasi kesulitan belajar membaca permulaan di sekolah dasar. Hasil penelitian ini hanya menganalisis kesulitan belajar membaca permulaan dilihat dari kegiatan dan aktifitas proses pembelajaran dan serta kebutuhan guru untuk membantu menstimulasi kesulitan pembelajaran.

\section{SIMPULAN}

Peserta didik sering terbalik membedakan huruf dan sulit dalam mengikuti perintah yang diberikan secara lisan. Cara yang dilakukan guru dalam menstimulasi dengan menyediakan media dan metode yang akan membantu proses membaca dan diberi latihan membaca. Diperlukan pengembangan model baru, strategi ataupun media inovatif sebagai sarana alternatif untuk membantu menstimulasi kesulitan belajar membaca permulaan di sekolah dasar.

\section{DAFTAR PUSTAKA}

Akın, F., Koray, Ö., \& Tavukçu, K. (2015). How Effective is Critical Reading in the Understanding of Scientific Texts? Procedia - Social and Behavioral Sciences, 174. https://doi.org/10.1016/j.sbspro.2015.01.915.

Amini, N., \& Suyadi, S. (2020). Media Kartu Kata Bergambar Dalam Meningkatkan Kemampuan Kosakata Anak Usia Dini. PAUDIA: Jurnal Penelitian Dalam Bidang Pendidikan Anak Usia Dini, 9(2), 119-129. https://doi.org/10.26877/paudia.v9i2.6702.

Aydın, G., \& Bağcı Ayrancı, B. (2018). Reading Preferences of Middle School Students. World Journal of Education, 8(2), 127. https://doi.org/10.5430/wje.v8n2p127.

Azis, M. (2019). Analisis Kesulitan Belajar Membaca dan Menulis Permulaan PAUD Di Kelompok Bermain Fun Islamic School. Al-Athfaal: Jurnal Ilmiah Pendidikan Anak Usia Dini, 2(2). https://doi.org/10.24042/ajipaud.v2i2.5927.

Baba, J., \& Rostam Affendi, F. (2020). Reading Habit and Students' Attitudes Towards Reading: A Study of Students in the Faculty of Education UiTM Puncak Alam. Asian Journal of University Education, 16(1), 109. https://doi.org/10.24191/ajue.v16i1.8988.

Balan, L., Yuen, T., \& Mehrtash, M. (2019). Problem-Based Learning Strategy for CAD Software Using Free-Choice and Open-Ended Group Projects. Procedia Manufacturing, 32, 339-347. https://doi.org/10.1016/j.promfg.2019.02.223.

Bursali, H., \& Yilmaz, R. M. (2019). Effect of augmented reality applications on secondary school students' reading comprehension and learning permanency. Computers in Human Behavior, 95. https://doi.org/10.1016/j.chb.2019.01.035.

Calhoon, M. B., Sandow, A., \& Hunter, C. V. (2010). Reorganizing the instructional reading components: Could 
there be a better way to design remedial reading programs to maximize middle school students with reading disabilities' response to treatment? Annals of Dyslexia, 60(1). https://doi.org/10.1007/s11881009-0033-X.

Capellini, S. A., César, A. B. P. D. C., \& Germano, G. D. (2015). Early identification of reading problems: Preliminary study with students of 1st grade. Procedia - Social and Behavioral Sciences, 174, 1351-1355. https://doi.org/https://doi.org/10.1016/j.sbspro.2015.01.758.

Chotitham, S., \& Wongwanich, S. (2014). The Reading Attitude Measurement for Enhancing Elementary School Students' Achievement. Procedia - Social and Behavioral Sciences, 116, 3213-3217. https://doi.org/10.1016/j.sbspro.2014.01.737.

Christianti, M. (2013). Membaca dan Menulis Permulaan Untuk Anak Usia Dini. Jurnal Pendidikan Anak, 2(2). https://doi.org/10.21831/jpa.v2i2.3042.

Chukwu, N. E., Okoye, U. O., Onyeneho, N. G., \& Okeibunor, J. C. (2019). Coping strategies of families of persons with learning disability in Imo state of Nigeria. Journal of Health, Population, and Nutrition, 38(1). https://doi.org/10.1186/s41043-019-0168-2.

Cluley, V. (2018). From "Learning disability to intellectual disability"-Perceptions of the increasing use of the term "intellectual disability" in learning disability policy, research and practice. British Journal of Learning Disabilities, 46(1). https://doi.org/10.1111/bld.12209.

Cluley, V., Fyson, R., \& Pilnick, A. (2020). Theorising disability: a practical and representative ontology of learning disability. Disability and Society, 35(2). https://doi.org/10.1080/09687599.2019.1632692.

Darnis. (2018). Aplikasi Montessori Dalam Pembelajaran Membaca, Menulis Dan Berhitung Tingkat Permulaan Bagi Anak Usia Dini. Jurnal Caksana: Pendidikan Anak Usia Dini, 1(1). https://doi.org/10.31326/jcpaud.v1i01.3.

Febliza, A., \& Okatariani, O. (2020). The Development of Online Learning Media by Using Moodle for General Chemistry Subject. Journal of Educational Science and Technology (EST), 6(1), 40. https://doi.org/10.26858/est.v6i1.12339.

Friedman, L. W., \& Friedman, H. H. (2013). Using social media technologies to enhance online learning. Journal of Educators Online, 10(1). https://doi.org/10.9743/JE0.2013.1.5.

Gading, I. K., Magta, M., \& Pebrianti, F. (2019). Pengaruh Metode Suku Kata Dengan Media Kartu Kata Bergambar Terhadap Kemampuan Membaca Permulaan. Mimbar Ilmu, 24(3). https://doi.org/10.23887/mi.v24i3.21417.

Hamid, M. A., Aribowo, D., \& Desmira, D. (2017). Development of learning modules of basic electronics-based problem solving in Vocational Secondary School. Jurnal Pendidikan Vokasi, 7(2), 149. https://doi.org/10.21831/jpv.v7i2.12986.

Haromi, F. A. (2014). Teaching through Appraisal: Developing Critical Reading in Iranian EFL Learners. Procedia Social and Behavioral Sciences, 98(6). https://doi.org/10.1016/j.sbspro.2014.03.398.

Heidari, K. (2020). Critical thinking and EFL learners' performance on textually-explicit, textually-implicit, and script-based reading items. Thinking Skills and Creativity, 37. https://doi.org/10.1016/j.tsc.2020.100703.

Hermansyah, A. K., Tembang, Y., \& Purwanty, R. (2019). Penggunaan Media Kartu Warna Kata untuk Meningkatkan Kemampuan Membaca Permulaan Siswa Kelas I SD Inpres Gudang Arang Merauke. Musamus (Journal of Primary Education), 1(2), 104-115. https://doi.org/10.35724/musjpe.v1i2.1468.

Kurniawati, R. T., \& Koeswanti, H. D. (2020). Pengembangan Media Buku Cerita Bergambar Untuk Meningkatkan Kemampuan Membaca Siswa Kelas 1 Sekolah Dasar. Didaktika Tauhidi: Jurnal Pendidikan Guru Sekolah Dasar, 7(1). https://doi.org/10.30997/dt.v7i1.2634.

Lin, L., \& Li, M. (2018). Optimizing learning from animation: Examining the impact of biofeedback. Learning and Instruction, 55. https://doi.org/10.1016/j.learninstruc.2018.02.005.

Lin, P. H., Su, Y. N., \& Huang, Y. M. (2019). Evaluating reading fluency behavior via reading rates of elementary school students reading e-books. Computers in Human Behavior, 100, 258-265. https://doi.org/10.1016/j.chb.2018.10.004.

Maula, N. R., \& Fatmawati, L. (2020). Pengembangan Media Pembelajaran Kayaku (Kayanya Alam Negeriku) Berbasis STEM Kelas IV Sekolah Dasar. Jurnal Ilmiah Sekolah Dasar, 4(1), 97. https://doi.org/10.23887/jisd.v4i1.22351.

Mayarnimar, \& Taufina. (2017). Validity Analysis of the VARK (Visual, Auditory, Read-Write, and Kinesthetic) Model - Based Basic Reading and Writing Instructional Materials for the 1st Grade Students of Elementary School. Atlantis Press, 118, 870-874. https://doi.org/10.2991/icset-17.2017.141.

McGill-Franzen, A., \& Allington, R. L. (2010). Handbook of reading disability research. In Handbook of Reading Disability Research. https://doi.org/10.4324/9780203853016.

Memiş, A. D., \& Kandemir, H. (2019). The Relationship Between the Study Habits and Attitudes and Metacognitive Reading Comprehension Self-Awareness, Reading Comprehension, Reading Attitudes. World Journal of Education, 9(4), 133. https://doi.org/10.5430/wje.v9n4p133. 
Nani, \& Evinna. (2019). Analisis Kesulitan Belajar Siswa Pada Pembelajaran Bahasa Indonesia Di Kelas V SDN 12 Singkawang. Journal Of Educational Review and Research, 2(1). https://doi.org/10.26737/jerr.v2i1.1853.

Nootens, P., Morin, M. F., Alamargot, D., Gonçalves, C., Venet, M., \& Labrecque, A. M. (2019). Differences in attitudes toward reading: A survey of pupils in grades 5 to 8. Frontiers in Psychology, 9(JAN), 1-13. https://doi.org/10.3389/fpsyg.2018.02773.

Nugrahanto, S., \& Zuchdi, D. (2019). Indonesia PISA Result and Impact on The Reading Learning Program in Indonesia. International Conference on Interdisciplinary Language, Literature and Education (ICILLE 2018), 297(0), 373-377. https://doi.org/10.2991/icille-18.2019.77.

Nurrohmah, F., Putra, F. G., \& Farida, F. (2018). Development of Sparkol Video Scribe Assisted Learning Media. Formatif: Jurnal Ilmiah Pendidikan MIPA, 8(3), 233-250. https://doi.org/10.30998/formatif.v8i3.2613.

Nurtanto, M., Sofyan, H., Fawaid, M., \& Rabiman, R. (2019). Problem-based learning (PBL) in industry 4.0: Improving learning quality through character-based literacy learning and life career skill (LL-LCS). Universal Journal of Educational Research, 7(11), 2487-2494. https://doi.org/10.13189/ujer.2019.071128.

Oktadiana, B. (2019). Analisis Kesulitan Belajar Membaca Permulaan Siswa Kelas Ii Pada Mata Pelajaran Bahasa Indonesia Di Madrasah Ibtidaiyah Munawariyah Palembang. Jurnal Ilmniah PGMI, 5(2). https://doi.org/10.19109/jip.v5i2.3606.

Peura, P., Aro, T., Räikkönen, E., Viholainen, H., Koponen, T., Usher, E. L., \& Aro, M. (2021). Trajectories of change in reading self-efficacy: A longitudinal analysis of self-efficacy and its sources. Contemporary Educational Psychology, 64(January). https://doi.org/10.1016/j.cedpsych.2021.101947.

Pilkington, E., Sage, K., Saddy, J. D., \& Robson, H. (2019). What can repetition, reading and naming tell us about Jargon aphasia? Journal of Neurolinguistics, 49. https://doi.org/10.1016/j.jneuroling.2018.08.003.

Rabgay, T. (2018). The effect of using cooperative learning method on tenth grade students' learning achievement and attitude towards biology. International Journal of Instruction, 11(2), 265-280. https://doi.org/10.12973/iji.2018.11218a.

Rajab, H., \& Al-Sadi, A. (2015). An Empirical Study of Reading Habits and Interest of Saudi University EFL Learners. International Journal of Linguistics, 1-17. https://doi.org/10.5296/ijl.v7i2.7034.

Reilly, C. A. (2021). Reading risk: Preparing students to develop critical digital literacies and advocate for privacy in digital spaces. Computers and Composition, 61. https://doi.org/10.1016/j.compcom.2021.102652.

Rekysika, N. S., \& Haryanto, H. (2019). Media Pembelajaran Ular Tangga Bilangan Untuk Meningkatkan Kemampuan Kognitif Anak Usia 5-6 Tahun. Cakrawala Dini: Jurnal Pendidikan Anak Usia Dini, 10(1), 5661. https://doi.org/10.17509/cd.v10i1.16000.

Saonah, S. (2018). Meningkatkan Kemampuan Membaca dan Menulis Permulaan Dengan Media Gambar Di Kelas I SD Negeri 222 Pasir Pogor. Jurnal Elementaria Edukasia, 1(1). https://doi.org/10.31949/jee.v1i1.812.

Suryawati, E., Suzanti, F., Zulfarina, Putriana, A. R., \& Febrianti, L. (2020). The implementation of local environmental problem-based learning student worksheets to strengthen environmental literacy. Jurnal Pendidikan IPA Indonesia, 9(2), 169-178. https://doi.org/10.15294/jpii.v9i2.22892.

Suwana, I. G. G., Artini, L. P., \& Piscayanti, K. S. (2013). The use of R.A.P. paraphrasing strategy to improve students' reading comprehension at class X.A3 in SMKN 2 Singaraja in academic year 2013/2014. Jurnal Pendidikan Bahasa Inggris Undiksha, 1(1). https://doi.org/10.23887/jpbi.v1i1.3859.

Talebi, M., \& Marzban, A. (2015). The Effect of Teaching Critical Reading Strategies on Advanced Iranian EFL Learners' Vocabulary Retention. Theory and Practice in Language Studies, 5. https://doi.org/10.17507/tpls.0503.17.

Tse, W. S., Choi, L. Y. A., \& Tang, W. S. (2019). Effects of video-based flipped class instruction on subject reading motivation. British Journal of Educational Technology, 50(1), 385-398. https://doi.org/10.1111/bjet.12569.

Valverde-Berrocoso, Garrido-Arroyo, M. d., Burgos-Videla, C., \& Morales-Cevallos. (2020). Trends in Educational Research about e-Learning: A Systematic Literature Review. Sustainability, 12(12). https://doi.org/10.3390/su12125153.

Vuong, Q. H., Le, A. V., La, V. P., Vuong, T. T., Do, T. H., Vuong, H. M., Do, D. L., Hoang, P. H., Vu, T. H., Ho, M. T., \& Ho, M. T. (2019). A dataset of vietnamese junior high school students' reading preferences and habits. Data, 4(49), 1-12. https://doi.org/10.3390/data4020049.

Widyaningrum, H. K., \& Hasanudin, C. (2019). Kajian Kesulitan Belajar Membaca Menulis Permulaan (MMP) di Sekolah Dasar [Study of Difficulty Learning to Read Beginning Writing (MMP) in Primary School]. Pedagogia: Jurnal Pendidikan, 8(2), 189-200. https://doi.org/10.21070/pedagogia.v8i2.2219.

Widyowati, F. T., Rahmawati, I., \& Priyanto, W. (2020). Pengembangan Media Pembelajaran Membaca Mengeja Berbasis Aplikasi untuk Kelas 1 Sekolah Dasar. International Journal of Community Service Learning, 4(4), 332-337. https://doi.org/10.23887/ijcsl.v4i4.

Windrawati, W., Solehun, \& Gafur, H. (2020). Analisis Faktor Penghambat Belajar Membaca Permulaan pada Siswa Kelas 1 SD Inpres 141 Matalamagi Kota Sorong. Jurnal Papeda, 2(1), 10-16. 
https://doi.org/10.36232/jurnalpendidikandasar.v2i1.405.

Yulianingsih, W., Suhanadji, S., Nugroho, R., \& Mustakim, M. (2020). Keterlibatan Orangtua dalam Pendampingan Belajar Anak selama Masa Pandemi Covid-19. Jurnal Obsesi: Jurnal Pendidikan Anak Usia Dini, 5(2), 1138-1150. https://doi.org/10.31004/obsesi.v5i2.740.

Yunita, Y., Fitri, F., \& Zulfahita, Z. (2017). Peningkatan Keterampilan Membaca Ekstensif Menggunakan Model Pembelajaran Reciprocal Teaching pada Siswa Kelas VIII D MTs Negeri Singkawang Tahun Ajaran 2016/2017. JP-BSI (Jurnal Pendidikan Bahasa Dan Sastra Indonesia), 2(1), 12-17. https://doi.org/10.26737/jp-bsi.v2i1.231.

Zarić, J., Hasselhorn, M., \& Nagler, T. (2021). Orthographic knowledge predicts reading and spelling skills over and above general intelligence and phonological awareness. European Journal of Psychology of Education, 36(1), 21-43. https://doi.org/10.1007/s10212-020-00464-7. 